\title{
FADS Gene Cluster Polymorphisms: Important Modulators of Fatty Acid Levels and Their Impact on Atopic Diseases
}

\author{
Eva Lattka ${ }^{a}$ Thomas Illig $^{\text {a Joachim Heinrich }}{ }^{a}$ Berthold Koletzko ${ }^{b}$ \\ a Institute of Epidemiology, Helmholtz Zentrum München, German Research Center for Environmental Health,

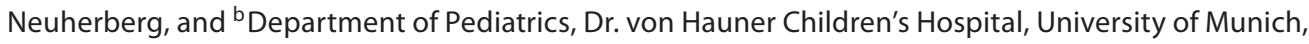 \\ Munich, Germany
}

\section{Key Words}

Arachidonic acid $\cdot$ Atopy $\cdot \Delta^{5}$ desaturase $\cdot \Delta^{6}$ desaturase $\cdot$ Single nucleotide polymorphism

\begin{abstract}
Long-chain polyunsaturated fatty acids (LC-PUFAs) play an important role in several physiological processes and their concentration in phospholipids has been associated with several complex diseases, such as atopic disease. The level and composition of LC-PUFAs in the human body is highly dependent on their intake in the diet or on the intake of fatty acid precursors, which are endogenously elongated and desaturated to physiologically active LC-PUFAs. The most important enzymes in this reaction cascade are the $\Delta^{5}$ and $\Delta^{6}$ desaturase. Several studies in the last few years have revealed that single nucleotide polymorphisms (SNPs) in the 2 desaturase encoding genes (FADS1 and FADS2) are highly associated with the concentration of $\omega-6$ and $\omega-3$ fatty acids, showing that beside nutrition, genetic factors also play an important role in the regulation of LC-PUFAs. This review focuses on current knowledge of the impact of genetic polymorphisms on LC-PUFA metabolism and on their potential role in the development of atopic diseases.
\end{abstract}

Copyright $\odot 2009$ S. Karger AG, Base

\section{KARGER}

Fax +4161306 1234 E-Mail karger@karger.ch www.karger.com
(C) 2009 S. Karger AG, Basel

1661-6499/09/0023-0119\$26.00/0

Accessible online at:

www.karger.com/jnn

\section{Introduction}

Polyunsaturated fatty acids (PUFAs) have a major impact on human health. The composition of PUFAs in phospholipids has, among other complex diseases, been associated with the development of allergies [1-3]. The biological effects of PUFAs are thought to be mediated by the availability of long-chain polyunsaturated fatty acids (LC-PUFAs) with $\geq 20$ carbon atoms and $\geq 3$ double bonds, such as the $\omega-6$ LC-PUFA arachidonic acid (20: $4 \omega-6)$, the $\omega-3$ LC-PUFAs eicosapentaenoic acid (20:

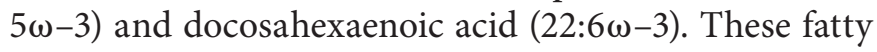
acids have several important functions in human metabolism. The composition of LC-PUFAs such as arachidonic acid and docosahexaenoic acid in phospholipids influences the integrity and fluidity of cell membranes. On the molecular level, LC-PUFAs fulfill several other central functions, such as acting as second messengers in intracellular signaling pathways or regulating transcription. In addition, LC-PUFAs are precursors for eicosanoids (leukotrienes and prostaglandins) which play an important role in inflammatory processes [4].

Sufficient dietary supply with LC-PUFAs is therefore pivotal in every stage of human life because it has a significant effect on blood and tissue LC-PUFA contents [5]. Besides its predominant endogenous synthesis from $\omega-6$ fatty acid precursors, arachidonic acid is contained in meats and eggs, whereas marine foods are an important

Eva Lattka, M.Sc., Institute of Epidemiology, Helmholtz Zentrum München German Research Center for Environmental Health

Ingolstädter Landstrasse 1, DE-85764 Neuherberg (Germany)

Tel. +49893187 3527, Fax +498931874567

E-Mail eva.lattka@helmholtz-muenchen.de 


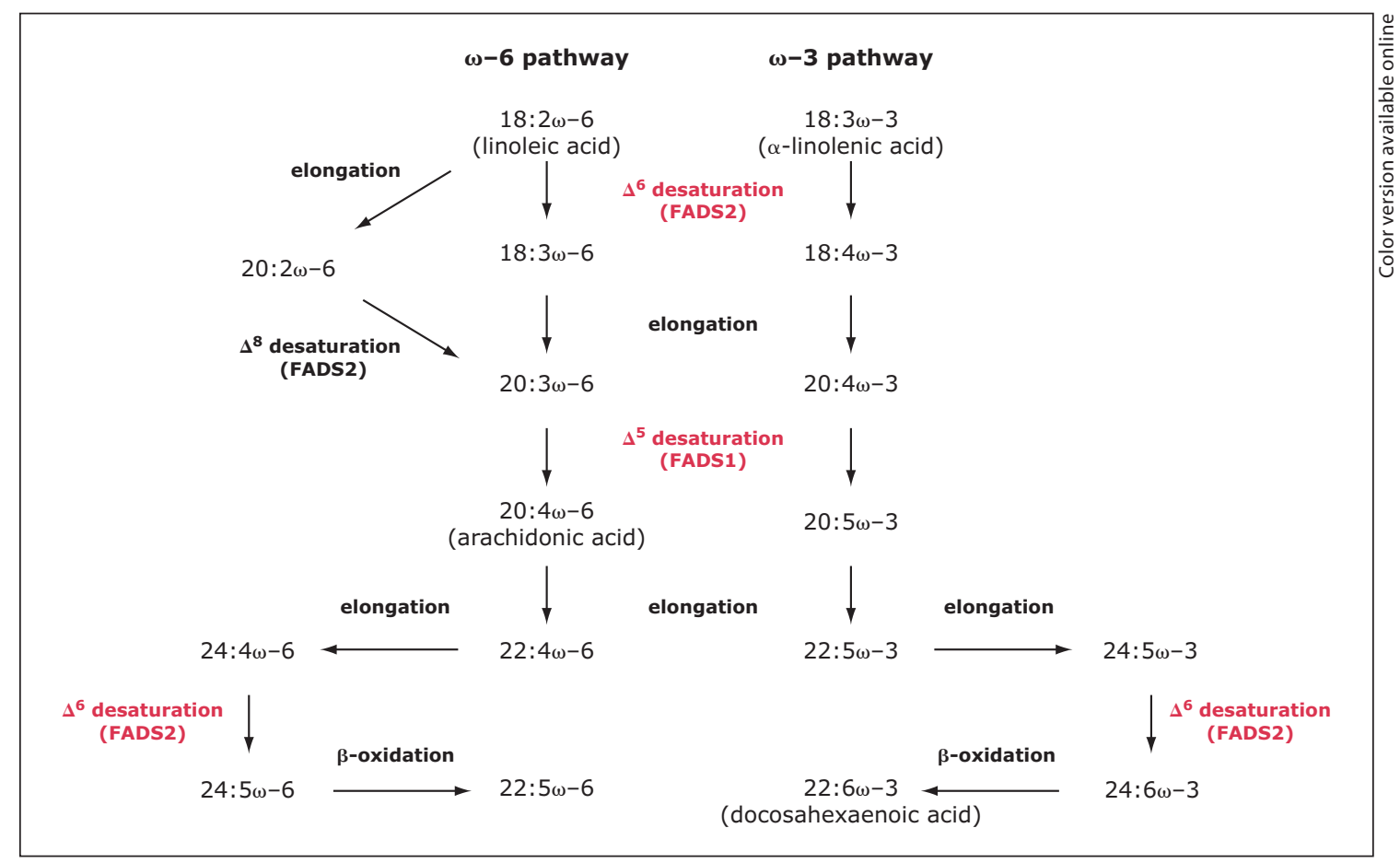

Fig. 1. Metabolic pathway of $\omega-6$ and $\omega-3$ LC-PUFAs in humans.

source for eicosapentaenoic acid and docosahexaenoic acid [6]. Adequate supply with dietary LC-PUFAs is of special importance for the fetus and neonate during pregnancy and lactation to ensure optimal visual and cognitive development. The supply of LC-PUFA to the fetus by the mother is mediated by maternal-fetal placental transfer during pregnancy $[7,8]$. Sufficient LC-PUFA can be supplied to the neonate by breastfeeding, which supplies preformed LC-PUFA for the child, and is therefore regarded as the preferred method of feeding during the first 6 months of life [9]. Besides the positive effects of LC-PUFAs on visual and cognitive development, a protective effect of LC-PUFAs on allergy development in children was shown in 2 different studies, assuming that early LC-PUFA provision may modulate immune responses $[10,11]$.

\section{The Important Role of $\Delta^{5}$ and $\Delta^{6}$ Desaturase, Encoded by FADS1 and FADS2, in Endogenous Production of LC-PUFAs}

In addition to the dietary supply of preformed LC-PUFAs, they can also be derived by human metabolism from

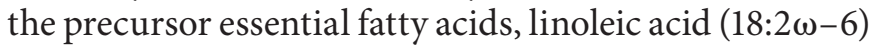

and $\alpha$-linolenic acid (18:3 $\omega-3)$, by consecutive desaturation and chain-elongation. The rate-limiting enzymes in this reaction cascade are the $\Delta^{5}$ and $\Delta^{6}$ desaturase. These enzymes are membrane-bound proteins with amino-terminal cytochrome $b 5$ domains carrying heme-binding motifs, 2 membrane-spanning domains, 3 His-box motifs and consist of 444 amino acids [12]. The human $\Delta^{5}$ desaturase shares $61 \%$ amino acid identity and $75 \%$ similarity to the human $\Delta^{6}$ desaturase [13]. The 2 enzymes catalyze the conversion of both $\omega-3$ and $\omega-6$ precursors to their respective LC-PUFA products in a reaction cascade [14]. In the first step, $\Delta^{6}$ desaturase converts linoleic acid $(18: 2 \omega-6)$ to $\gamma$-linolenic acid $(18: 3 \omega-6)$ in the $\omega-6$ pathway and $\alpha$-linolenic acid $(18: 3 \omega-3)$ to stearidonic acid $(18: 4 \omega-3)$ in the $\omega-3$ pathway by inserting an additional cis double bond at position 6 of the fatty acid chain. After an elongation step [resulting in dihomo- $\gamma$-linolenic acid $(20: 3 \omega-6)$ and eicosatetraenoic acid $(20: 4 \omega-3)$, respectively], $\Delta^{5}$ desaturase catalyzes the formation of ara-

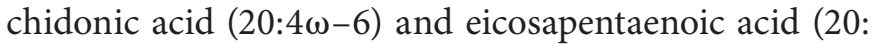
$5 \omega-3)$. These molecules are either converted into eicosanoids or further elongated and desaturated, again with the help of a $\Delta^{6}$ desaturase $[4,15]$, resulting in several important LC-PUFAs, among them docosahexaenoic acid 
$(22: 6 \omega-3)$. Several studies have shown that the final desaturation step in 22:6 $\omega-3$ synthesis is catalyzed by the same $\Delta^{6}$ desaturase that acts also on 18-carbon PUFA substrates [15-17]. The fact that fibroblasts from a human case of $\Delta^{6}$ desaturase deficiency were unable to desaturate $18: 2 \omega-6$ or $24: 5 \omega-3$ support this hypothesis [18]. Although studies with human malignant cell lines suggested that separate $\Delta^{6}$ desaturases may act on these substrates $[19,20]$, no $\Delta^{6}$ desaturase isozyme specific to 24 -carbon fatty acids is known at this time. An overview of the desaturation pathway is given in figure 1. The human desaturases were first cloned in $1999[12,13]$ and the corresponding genes (FADS1 for $\Delta^{5}$ desaturase and FADS2 for $\Delta^{6}$ desaturase) were mapped to chromosome 11q12-13.1 of the human genome in 2000 [21], which shows conserved synteny to the mouse genomic region containing the murine fads 1 and $\mathrm{fads} 2$ genes on chromosome 19 [4]. The 2 human genes are arranged in a headto-head orientation and build a gene cluster together with a third desaturase gene, FADS3. It is assumed that, due to their similar exon/intron organization (12 exons and 11 introns) and a high degree of sequence homology, these 3 genes have arisen evolutionary from gene duplication [21]. While the function of the $\Delta^{5}$ and $\Delta^{6}$ desaturase, encoded by FADS1 and FADS2, respectively, is well characterized, the function of the protein product of the FADS3 gene is still unknown. Park et al. [22] identified several alternative splice forms of FADS3 that are expressed in many tissues showing changes in abundance in response to human neuronal cell differentiation, and hypothesized a tissue- or PUFA-specific role of FADS3 in LC-PUFA synthesis. $\Delta^{5}$ and $\Delta^{6}$ desaturase are expressed in the majority of human tissues, with highest levels in liver and, to a lesser extent, in the brain, heart and lung $[12,13]$. Studies on substrate specificity and enzyme kinetics of both enzymes exist, which have identified at least 5 substrates for the mammalian $\Delta^{6}$ desaturase so far $(18: 2 \omega-6$, $18: 3 \omega-3,24: 5 \omega-3,24: 4 \omega-6$ and 16:0) $[14,17,23-25]$ and showed an additional $\Delta^{8}$ desaturase activity of this en-

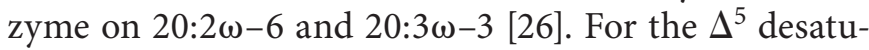
rase, no other substrates beside $20: 3 \omega-6$ and $20: 4 \omega-3$ are known to date, which speaks for a stricter substrate specificity of this enzyme.

The importance of $\Delta^{6}$ desaturase for the formation of LC-PUFAs and their influence on membrane integrity and fluidity was shown in a recent study by Stoffel et al. [27] who generated a $\mathrm{fads} 2^{-/-}$mouse. In this animal model, the membrane polarity of Sertoli and ovarian follicle cells was completely disturbed due to the lack of LC-PUFAs in knockout mice caused by the $\Delta^{6}$ desaturase defi- ciency. Furthermore, both male and female mice were infertile and eicosanoid synthesis was disturbed. However, the administration of a LC-PUFA-rich diet (either C20: $4 \omega-6$ or C20:5 $\omega-3 / \mathrm{C} 22: 6 \omega-3)$ enabled the $f a d s 2^{-/-}$mice to overcome the genetic defect, restored the fatty acid pattern in membrane lipids and rescued spermatogenesis as well as normal follicle development. Similarly, eicosanoid synthesis was restored by administration of arachidonic acid. Similar effects were observed in another $f a d s 2^{-/-}$ mouse by Stroud et al. [28], who additionally reported ulcerative dermatitis and ulceration of the small intestine in their mice. A fads1 knockout mouse has not been described until now.

A female patient with reduced $\Delta^{6}$ desaturase activity, probably due to an inherited deficiency in $\Delta^{6}$ desaturase, was described by Williard et al. [18]. This patient developed severe symptoms shortly after birth, including corneal ulceration, feeding intolerance, growth failure, skin abnormalities (cheilosis, dystrophic nails and perineal dermatitis) and photophobia. Neurological examinations were normal. Due to the abnormalities in her plasma fatty acid composition, the patient was provided with blackcurrant seed oil, fish oil capsules and a vitamin A supplement as fatty acid therapy, which was subsequently switched to a mixture of $20: 4 \omega-6$ and docosahexaenoic acid. This therapy led to growth acceleration until normal height for her age, and an improvement of skin abnormalities.

\section{Candidate Gene Studies Reveal an Association between FADS Gene Cluster Polymorphisms and LC-PUFA Levels in Different Tissues}

The important function of the $\Delta^{5}$ and $\Delta^{6}$ desaturase in the synthesis of LC-PUFAs made it a perfect candidate gene for association studies of FADS gene cluster polymorphisms with PUFA and LC-PUFA levels in human tissues, to investigate the role of DNA variants on desaturase activity. The human FADS gene cluster (including FADS1, FADS2 and FADS3) comprises $91.9 \mathrm{~kb}$ on chromosome 11q12-13.1 with a head-to-head orientation of FADS1 and FADS2 and a tail-to-tail orientation of FADS2 and FADS3 (fig. 2). All 3 genes have a similar exon/intron organization (12 exons, 11 introns), with FADS1 spanning a 17.2-kb region, FADS2 a 39.1-kb region and FADS3 an $18.0-\mathrm{kb}$ region. Introns 1 of FADS1 and FADS2 are separated by an $11.4-\mathrm{kb}$ region and FADS3 is located in the $6.0-\mathrm{kb}$ telomeric side of FADS2. In this 91.9-kb region, around 500 single nucleotide polymorphisms (SNPs) are 


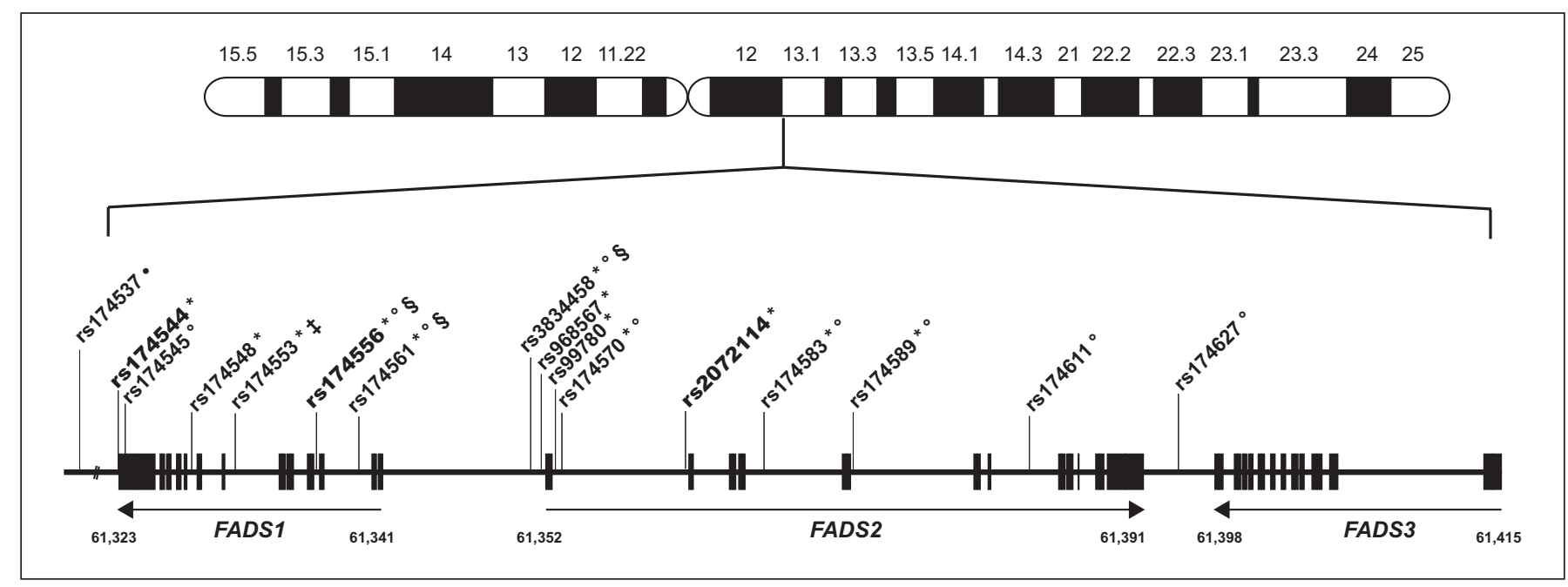

Fig. 2. Schematic structure of the human FADS gene cluster located on chromosome 11 and location of SNPs showing highest associations with fatty acid levels in different studies. SNPs with highest associations with fatty acids in the study of Schaeffer et al. [29] are marked with an asterisk $\left({ }^{*}\right)$. Most significant SNPs in all association studies which found a significant association of FADS gene cluster SNPs and fatty acid levels are indicated as follows:
${ }^{\circ}$ Malerba et al. [30]; ${ }^{\S}$ Rzehak et al. [31]; ${ }^{\ddagger}$ Xie and Innis [32]; ${ }^{\bullet}$ Tanaka et al. [33]. SNPs that were most significantly associated with allergic rhinitis and atopic eczema in the study of Schaeffer et al. [29] are marked in bold. The genomic position is given for each of the 3 FADS genes (numbers below gene names). SNP rs174537 is located $8.6 \mathrm{~kb}$ upstream of the FADS1 gene (the change in scaling is indicated by //). annotated in the NCBI database (dbSNP build 130). Schaeffer et al. [29] analyzed 18 selected SNPs in and around the FADS1 and FADS2 genes for association with fatty acids in serum phospholipids for the first time in 727 German probands of the European Community Respiratory Health Survey I. After calculation of linkage disequilibrium (LD) between the analyzed SNPs, which revealed a highly preserved LD block in the 48 -kb genomic region from SNP rs174544 to SNP rs174589 (fig. 2), 3 redundant markers $\left(\mathrm{r}^{2}>0.99\right)$ were excluded from the analysis. Association analysis of the 15 remaining SNPs with $11 \omega-6$ and $\omega-3$ fatty acids showed highly significant results for 11 SNPs, which are all located in the identified LD block, and all fatty acids (all $\mathrm{p}<1.0 \times 10^{-13}$ ) except for docosapentaenoic acid $(22: 5 \omega-6)$ and docosahexaenoic acid $(22: 6 \omega-3)$. Carriers of the minor alleles of these 11 SNPs (rs174544, rs174553, rs174556, rs174561, rs3834458, rs968567, rs99780, rs174570, rs2072114, rs174583, and rs174589) had enhanced levels of 18:2 $\omega-6$, $20: 2 \omega-6,20: 3 \omega-6$, and $18: 3 \omega-3$ and decreased levels of $18: 3 \omega-6,20: 4 \omega-6,22: 4 \omega-6,20: 5 \omega-3$, and $22: 5 \omega-3$. Fatty acids belonging to other pathways, such as oleic acid

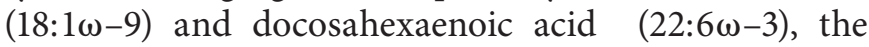
source of which is mainly nutritional, did not show significant associations with the genetic variants. For the 4
SNPs beyond the LD block, the association with fatty acid levels weakened or vanished completely. Haplotype analysis was performed using all 11 associated SNPs as well as a subgroup of the first 5 strongly correlated SNPs in the gene cluster, and association results were in line with the findings of the single SNP analysis. The variability in fatty acid levels explained by the genetic variants for the 11 analyzed SNPs varied from exceptionally high for arachidonic acid (28.5\%) to low for $22: 5 \omega-6$ and $22: 6 \omega-3$ (1-3\%). This first association study on FADS polymorphisms with fatty acid levels in serum phospholipids clearly showed a significant association with an accumulation of desaturase substrates and a decline of desaturase products due to the minor alleles of the associated SNPs. The authors concluded that this might be the case as a result of a decline in the transcriptional levels or in the conversion rates of the desaturases in subjects carrying the minor alleles. Speculation about the possible causal SNPs revealed rs174561 and rs3834458 as the most interesting variants, because these are located in $\mathrm{CpG}$ islands as well as in hypothetical promoter regions. However, due to the highly preserved LD structure in the gene cluster region, statements about the causal SNP can hardly be made, because 1 causal SNP is sufficient to cause associations in all others. Furthermore, it is also possible that the 
functionally relevant variant was not among the ones that were directly analyzed, but is just highly correlated with the analyzed SNPs. Another interesting issue in this paper was the association of FADS gene cluster polymorphisms with IgE levels, allergic rhinitis and atopic eczema. No significant association was observed for genotypes or haplotypes with total or specific IgE levels. For allergic rhinitis and atopic eczema, protective odds ratios for carriers of the minor alleles of several SNPs were obtained; however, after correction for multiple testing, the association did not remain significant. Although statistical significance concerning atopic diseases could not be proved in this study, it suggests a role of the desaturases in the development of atopy. The role of FADS genes in atopic diseases will be discussed again later in this review.

The association between FADS gene cluster polymorphisms and fatty acids was replicated in 3 independent studies, which additionally showed an association with fatty acids in plasma, erythrocyte membrane and breast milk phospholipids, beside the already known association with serum phospholipids [30-32]. The analysis of erythrocyte membrane phospholipids is a valuable tool for the study of fatty acid metabolism, because their fatty acid composition resembles that of circulating lipoproteins, which are assembled in the liver. Furthermore, long-term effects of fatty acid regulation can be determined better in erythrocyte membranes, because the fatty acid composition of membranes is less influenced by short-term variations in dietary intake than serum/plasma phospholipids. The first replication study [30] analyzed 13 SNPs spanning the complete FADS gene cluster (including FADS3) in 658 north Italian subjects of the Verona Heart Project. Highly significant results were observed for the majority of the analyzed FADS1 and FADS2 SNPs and arachidonic acid in serum as well as erythrocyte membrane phospholipids $\left(\mathrm{p}<1.0 \times 10^{-4}\right)$. Up- or down-regulation of all analyzed fatty acids dependent on the allele was in accordance with the results shown by Schaeffer et al. [29], although only $18: 3 \omega-3$ and $20: 2 \omega-6$ in serum phospholipids and $18: 2 \omega-6$ and $20: 2 \omega-6$ in erythrocyte membranes reached significance. Haplotype analysis revealed a significant association between the constructed FADS cluster haplotypes and the level of arachidonic acid in serum and erythrocytes $\left(\mathrm{p}<8.9 \times 10^{-4}\right)$, but no significant association with any other fatty acid. This study showed evidence that FADS polymorphisms do not only contribute to the variability of short-term fatty acid levels in serum, but also to the variability in medium-term compartments, such as erythrocyte mem- branes. The second replication study, which was performed at the same time by Rzehak et al. [31], confirmed the results from the 2 previous studies by analyzing the association of 3 FADS SNPs (rs174556, rs174561, and rs334458) with plasma and erythrocyte membrane fatty acids in 535 subjects (for plasma) and 163 subjects (for erythrocyte membranes) of the Bavarian Nutrition Survey II. To address the question whether FADS gene cluster polymorphisms have an influence on the fatty acid composition of human breast milk, Xie and Innis [32] genotyped 4 SNPs in FADS1 and FADS2 in 54 women, for whom data on fatty acid concentrations in breast milk 1 month postpartum were available. The authors found significant associations between SNP rs174553 and the medium-chain fatty acid 14:0 ( $\mathrm{p}$ value $=4.6 \times 10^{-2}$ ), which is the end product of the de novo fatty acid synthase complex in the mammary gland and $18: 1 \omega-7(\mathrm{p}=$ $1.0 \times 10^{-3}$ ), which is the $\Delta^{9}$ desaturation-elongation product of 16:0. Medium-chain fatty acids (10:0, 12:0, 14:0) had decreased levels for the G allele of rs174553, whereas only 14:0 was statistically significant. $\Delta^{9}$ desatu-

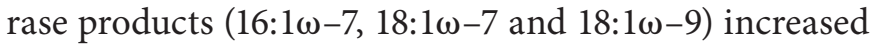
in case of the $G$ allele with significance only observed for $18: 1 \omega-7$. For SNP rs174553, significant differences in PUFA concentration were obtained for $20: 2 \omega-6,20$ : $4 \omega-6,20: 5 \omega-3$ and $22: 5 \omega-3\left(\mathrm{p}<2.6 \times 10^{-2}\right)$. For SNP rs174575, concentrations of $20: 4 \omega-6,22: 5 \omega-6,20: 5 \omega-3$ and also, interestingly, $22: 5 \omega-3$ and $22: 6 \omega-3$ differed significantly depending on the allele $\left(\mathrm{p}<4.4 \times 10^{-2}\right)$. The direction of change in PUFA/LC-PUFA concentrations was the same as observed in the previous studies. Simultaneously, the authors analyzed the influence of FADS1 FADS2 polymorphisms on plasma phospholipid and erythrocyte ethanolamine phosphoglyceride fatty acids in 69 pregnant women at week 16 of gestation. They found significant associations between rs174553 and plasma $18: 2 \omega-6,20: 4 \omega-6,22: 5 \omega-3$ and $22: 5 \omega-6\left(\mathrm{p}<5.0 \times 10^{-3}\right)$. An association with plasma 20:4 $\omega-6$ was also found for $\operatorname{SNP} \operatorname{rs} 174575\left(\mathrm{p}=3.0 \times 10^{-3}\right)$. For erythrocyte ethanolamine phosphoglyceride fatty acids, an association between rs174553 and levels of 18:2 $\omega-6,20: 3 \omega-6,20: 4$ $\omega-6$ and $22: 4 \omega-6\left(\mathrm{p}<3.8 \times 10^{-2}\right)$ was observed, whereas no association with $\omega-3$ fatty acids was reported.

The results of these association studies have been strengthened by a genome-wide association study published by Tanaka et al. in 2009 [33], where the authors analyzed plasma levels of $6 \omega-3$ and $\omega-6$ fatty acids in 1,075 participants in the InCHIANTI study and found strongest associations in the FADS gene cluster. SNP rs174537, which is located at genomic position $61,309,256$ 
Table 1. Genetic association studies with associations between FADS polymorphisms and fatty acid concentrations

\begin{tabular}{|c|c|c|c|c|c|}
\hline Study & $\mathrm{n}$ & Most significant $\mathrm{SNP}(\mathrm{s})$ & SNP location & Associated metabolites & $\mathrm{p}$ (most significant metabolite) \\
\hline $\begin{array}{l}\text { Schaeffer et al. } \\
(2006)[29]\end{array}$ & 727 & $\begin{array}{l}\text { rs174544, rs174553, } \\
\text { rs174556, rs174561, } \\
\text { rs3834458, rs } 968567, \\
\text { rs99780, rs174570, } \\
\text { rs2072114, rs174583, } \\
\text { rs174589 }\end{array}$ & $F A D S 1 / 2$ & $\begin{array}{l}\text { fatty acids in serum } \\
\text { phospholipids }\end{array}$ & $\begin{array}{l}\text { single analysis: }<1.0 \times 10^{-13}(20: 4 \omega-6) \\
\text { haplotype analysis: } 3.7 \times 10^{-15}(20: 4 \omega-6)\end{array}$ \\
\hline $\begin{array}{l}\text { Malerba et al. } \\
(2008)[30]\end{array}$ & 658 & $\begin{array}{l}\text { rs174545, rs174556, } \\
\text { rs174561, rs3834458, } \\
\text { rs174570, rs174583, } \\
\text { rs174589, rs174611, } \\
\text { rs174627 }\end{array}$ & $F A D S 1 / 2 / 3$ & $\begin{array}{l}\text { fatty acids in serum } \\
\text { phospholipids and } \\
\text { erythrocyte membranes }\end{array}$ & $\begin{array}{l}\text { single analysis: }<1 \times 10^{-4} \\
(20: 4 \omega-6 \text { in serum and erythrocytes }) \\
\text { haplotype analysis: }<1 \times 10^{-4} \\
\left(20: 4 \omega-6 \text { in serum) and }<2 \times 10^{-4}\right. \\
(20: 4 \omega-6 \text { in erythrocytes })\end{array}$ \\
\hline $\begin{array}{l}\text { Rzehak et al. } \\
(2008)[31]\end{array}$ & $\begin{array}{l}163 \text { (plasma) } \\
535 \text { (erythrocytes) }\end{array}$ & $\begin{array}{l}\text { rs174556, rs174561, } \\
\text { rs3834458 }\end{array}$ & $F A D S 1 / 2$ & $\begin{array}{l}\text { fatty acids in plasma } \\
\text { phospholipids and } \\
\text { erythrocyte membranes }\end{array}$ & $\begin{array}{l}\text { single analysis: } 7.9 \times 10^{-10}(20: 3 \omega-6 \text { in } \\
\text { erythrocytes), plasma: data not shown } \\
\text { haplotype analysis: } 2.7 \times 10^{-9} \\
(20: 3 \omega-6 \text { in erythrocytes }) \text { and } 7.8 \times 10^{-11} \\
(20: 4 \omega-6 \text { in plasma })\end{array}$ \\
\hline $\begin{array}{l}\text { Xie et al. } \\
(2008)[32]\end{array}$ & $\begin{array}{l}69 \text { (plasma/ } \\
\text { erythrocytes) } \\
54 \text { (breast milk) }\end{array}$ & rs 174553 & FADS1 & $\begin{array}{l}\text { fatty acids in plasma } \\
\text { and erythrocyte } \\
\text { phospholipids and in } \\
\text { breast milk }\end{array}$ & $\begin{array}{l}\text { plasma : }<1 \times 10^{-3}(18: 2 \omega-6,20: 2 \omega-6 \text { and } \\
20: 4 \omega-6) \text {, } \\
\text { erythrocytes: }<1 \times 10^{-3}(20: 3 \omega-6), \\
\text { breast milk: } 1 \times 10^{-3}(18: 1 \omega-7)\end{array}$ \\
\hline $\begin{array}{l}\text { Tanaka et al. } \\
\text { (2009) [33] }\end{array}$ & $\begin{array}{l}1,210 \text { plus } \\
1,076 \text { (replication) }\end{array}$ & rs174537 & $\begin{array}{l}5^{\prime} \text { upstream } \\
\text { region of } F A D S 1\end{array}$ & plasma fatty acids & $\begin{array}{l}\text { initial study: } 5.95 \times 10^{-46}(20: 4 \omega-6) \\
\text { replication study: }<1.0 \times 10^{-3}(20: 4 \omega-6)\end{array}$ \\
\hline
\end{tabular}

in the $14.4 \mathrm{~kb} 5^{\prime}$ region of FADS1, showed the most significant association with arachidonic acid $(\mathrm{p}=5.95 \times$ $\left.10^{-46}\right)$. Individuals homozygous for the minor allele of rs174537 had lower concentrations of 20:4 $\omega-6$ compared to the homozygous carriers of the major allele. The SNP accounted for $18.6 \%$ of the variance in the concentration

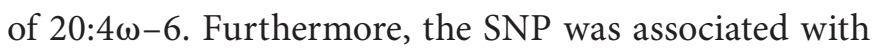
altered levels of $20: 2 \omega-6\left(\mathrm{p}=6.78 \times 10^{-9}\right)$ and $20: 5 \omega-3$ $\left(\mathrm{p}=1.04 \times 10^{-14}\right)$. The association with $18: 2 \omega-6$ and $18: 3 \omega-3$ did not reach genome-wide significance $(\mathrm{p}=$ $5.58 \times 10^{-7}$ and $2.76 \times 10^{-5}$, respectively) and there was no association with $22: 6 \omega-3$ at all. The effects of rs 174537 were confirmed in an independent sample of 1,076 participants of the GOLDN study in erythrocyte membranes. A summary of all association studies on FADS polymorphisms and fatty acid levels is given in table 1.

\section{FADS Gene Cluster Polymorphisms May Modulate the Development of Atopic Diseases}

The levels and composition of various PUFAs and LCPUFAs has been associated with the development of atopic diseases in numerous studies, although the direction of association differs among reports. Higher plasma levels of $18: 2 \omega-6$, and lower levels of $18: 3 \omega-6,20: 3 \omega-6$ and 20 : $4 \omega-6$ in adults and children with atopic eczema have been reported very early [34]. Several, but not all, following studies on diverse atopic disorders observed disturbances in $\omega-6$ and $\omega-3$ fatty acids [35-43]. A good review on the results of these studies is provided by Duchén and Björkstén [1]. Analyses of the phospholipid PUFA composition in chord blood and early infancy resulted in partly contrary findings about the prediction of atopic development during the first months of life, based on the fatty acid composition [44-48]. Despite small controversies in the different studies, it is widely assumed that atopy is related to a disturbed metabolism of $\omega-6$ and $\omega-3$ LC-PUFA [1]. A defect in the enzyme activity of the $\Delta^{6}$ desaturase has been suggested to be present early in atopic disease patients [49], due to the higher levels of 18 : $2 \omega-6$ and lower levels of its longer metabolites in atopic children and adults. This defect in enzyme activity would explain the proposed dysregulation of arachidonic acid metabolism in atopy [50]. Arachidonic acid is one of the main precursors of prostaglandins and leukotrienes [51] and activates allergic immune responses via its products, prostaglandin E2 and leukotriene B4 [52-56]. For $\omega-3$ fatty acids like eicosapentaenoic acid and docosahexaenoic acid, modulation of cytokine responses has also been 
shown [57], whereas dietary treatment with these $\omega-3$ fatty acids in inflammatory disorders suggests rather anti-inflammatory properties in contrast to the products of arachidonic acid [58].

One reason for the proposed defect in enzyme activity of the $\Delta^{6}$ desaturase, possibly leading to an imbalance between $\omega-6$ and $\omega-3$ LC-PUFAs and therefore to disturbed inflammatory processes, could be mutations or polymorphisms in the $\Delta^{6}$ desaturase encoding the FADS 2 gene. First concrete indications of a relation between the FADS genes and atopic diseases were provided by linkage studies $[59,60]$. In the first candidate gene study on the association of FADS polymorphisms with fatty acid composition in serum phospholipids, Schaeffer et al. [29] reported a lower prevalence of allergic rhinitis and atopic eczema in carriers of the rare alleles of several SNPs for the first time, although these associations were not significant after correction for multiple testing. No association was found for total and specific IgE levels.

An association between breastfeeding and the development of atopic manifestations early in life has been suggested repeatedly [61]. Several studies exist, which investigated the PUFA composition of human milk in relation to the atopic status of the mother $[62,63]$ and the development of atopic disease in children [47, 64, 65]. Although differences exist in the composition of colostrum, transitional and mature milk $[62,66]$, most studies agree on altered levels of $\omega-6$ and $\omega-3$ LC-PUFAs in milk of atopic mothers compared to non-atopic mothers [47, 62, 63]. The LC-PUFA composition of transitional human milk agrees especially well with the reported low levels of $\omega-6$ and $\omega-3$ LC-PUFAs in plasma $[35,36,40]$ and membrane phospholipids $[37,43,67]$ in atopic children and adults. The composition of LC-PUFAs in maternal milk affects the PUFA status of the child, as has been shown by several studies [68-70]. Those few studies dealing with the relationship between maternal milk PUFA composition and development of atopy in the children $[47,64,65]$ found contrary results on the influence of maternal milk $\omega-6$ LC-PUFA composition on the children's atopic status, but low levels of the $\omega-3$ LC-PUFAs 20:5 $\omega-3,22$ : $5 \omega-3$ and $22: 6 \omega-3$ in maternal milk seemed to be related to early childhood development of allergies. The ratio of $20: 4 \omega-6$ to $20: 5 \omega-3$ is consistently higher in milk from mothers of atopic children, suggesting a disturbed balance in the arachidonic acid and eicosapentaenoic acid metabolism in atopic patients, and corroborates the relationship between $\omega-3$ LC-PUFA metabolism and atopy $[1,47]$. Besides the influence of maternal diet and lifestyle on the fatty acid composition in human breast milk [71,
72], maternal FADS genotypes have a great influence as well, as was shown by Xie et al. [32]. It would therefore be very interesting if FADS polymorphisms modulate the development of atopic diseases in early childhood by regulating the fatty acid composition in breast milk. To our knowledge, not a single study has investigated a possible modulation of the relationship between LC-PUFAs in breast milk and atopic status of the child by FADS genotypes, although a $\Delta^{6}$ desaturase deficiency has been proposed in atopic subjects $[1,49]$. The inclusion of FADS genotypes in future cohort and intervention studies might help to understand the role of LC-PUFAs in allergy development better and may also lead to enhanced sensitivity and precision of such studies [6].

\section{Conclusion and Outlook}

This review focused on current knowledge of the effects of FADS gene cluster polymorphisms on fatty acid levels in different human tissues as well as the effect of these polymorphisms on the development of atopic diseases. FADS genotypes account for up to $28 \%$ of the variability observed for fatty acid levels [29]. Besides the regulation by dietary fatty acids and hormonal signals, FADS genotypes are important regulators of desaturase activity and thus the balance of $\omega-6$ and $\omega-3$ PUFAs and LC-PUFAs in the human body.

The integration of FADS genotypes into future studies on fatty acid-related phenotypes will help us to better understand the biological effects of PUFAs and LC-PUFAs. Large gene-nutrition-interaction studies on complex disorders like atopic diseases are urgently needed to determine the influence of FADS polymorphisms on the onset of such diseases in the context of individual dietary fatty acid intake and to understand the complex regulation mechanisms of desaturase activity by dietary and endogenous fatty acids as well as individual FADS genotypes. Based on the results of such studies, individualized dietary recommendations dependent on the FADS genotype might help to balance PUFA/LC-PUFA intake and availability and by this contribute to the prevention of the onset of fatty acid-related diseases such as atopy later in life.

Furthermore, the identification of the regulatory functional FADS variants will improve our understanding of the regulation pathways and might better explain the contribution of polymorphisms in the biological effects of LC-PUFAs. First results on functional effects of a FADS2 promoter polymorphism exist, where we were 

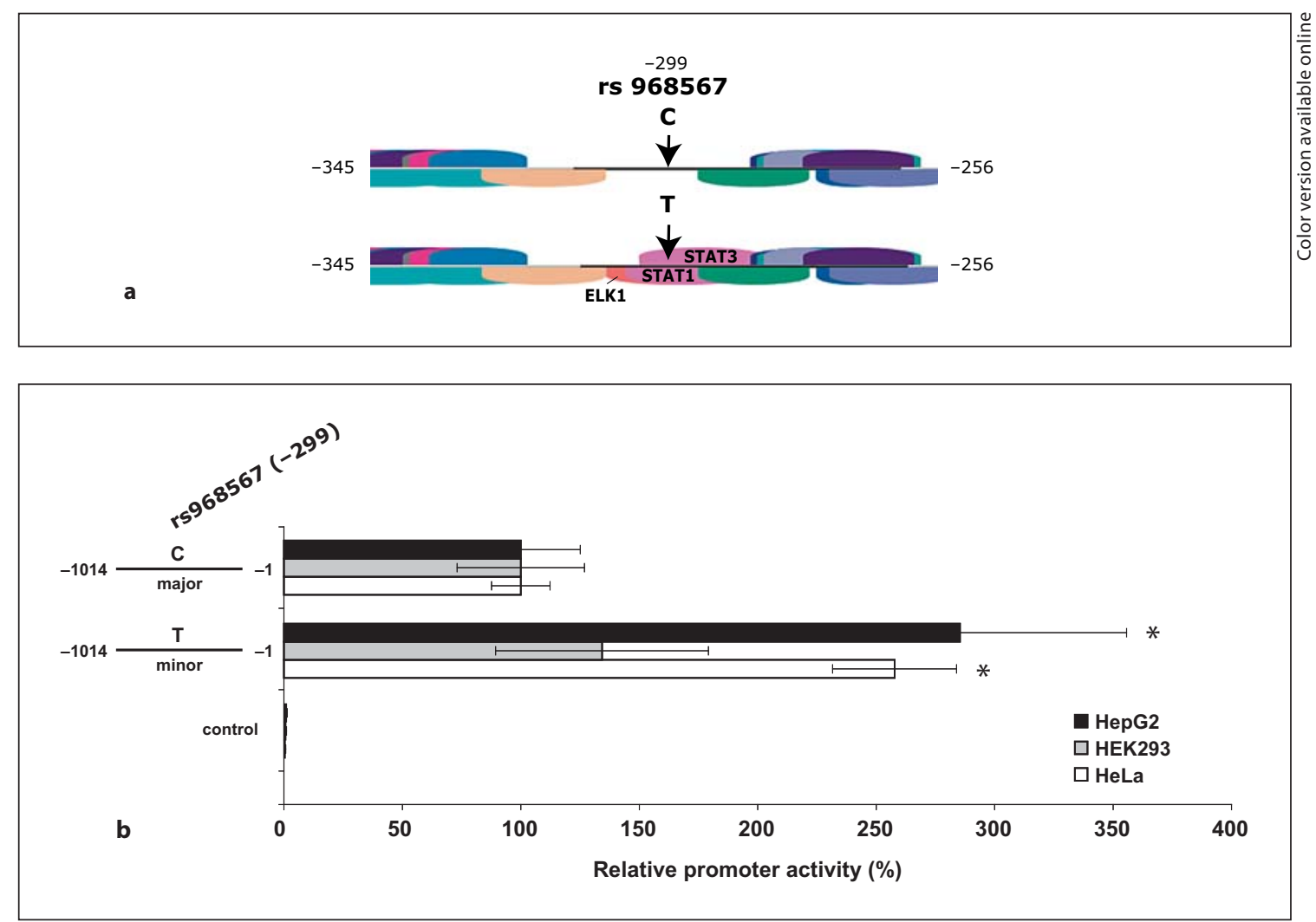

Fig. 3. Results on functional studies of FADS2 promoter SNP rs968567 [73], showing a regulatory function of this SNP. a Prediction of transcription factors binding sites by Genomatix MatInspector suggested allele-specific binding affinity of 3 transcription factors (ELK1, STAT1 and STAT3). A higher binding affinity of the ELK1 protein to this promoter region when the minor $\mathrm{T}$ allele of rs968567 is present could be verified by DNA affinity chromatography and immunoblotting (not shown). Numbers indicate the sequence position relative to the translation start site. b Rela- tive promoter activity of constructs of the human FADS2 gene promoter in 3 different human cell lines increased when the major $\mathrm{C}$ allele of rs968567 was replaced by the minor T allele, possibly due to increased binding of ELK1 transcription factor. Values represent the mean of 3 independent experiments performed in triplicates. Promoter activity of the construct with the major allele was used as reference and set at $100 \%$. Numbers indicate the relative position to the FADS2 translation start site. * Statistically significant, $\mathrm{t}$ test. able to show an increase in promoter activity and higher binding affinity of a specific transcription factor to the SNP-containing promoter region when the major allele was replaced by the minor allele in in vitro experiments [73] (fig. 3). The consequence of the observed effects on $\Delta^{6}$ desaturase expression or activity and its biological importance has to be analyzed in further studies.

In summary, the knowledge that FADS gene polymorphisms influence fatty acid levels in human tissues and by this might modulate the characteristics of fatty acidrelated phenotypes, is hopefully just the starting shot for further studies on the interaction of nutritional and genetic factors and their concerted effect on complex phenotypes like atopic diseases.

\section{Acknowledgments}

We gratefully acknowledge partial financial support from the Commission of the European Communities, Specific RTD Programme 'Quality of Life and Management of Living Resources', within the 6th Framework Programmes EARNEST, Food-CT2005-007036, and EURRECA (FP6-036196-2), and within the 7th Framework Programme NUTRIMENTHE (FP7-212652). This manuscript does not necessarily reflect the views of the Commission and in no way anticipates future policy in this area. We furthermore thank the German Federal Ministry of Education and Research (01GS0485) for financial support. B.K. is the recipient of a Freedom to Discover Award from the Bristol-Myers-Squibb Foundation (New York, N.Y., USA). 


\section{References}

1 Duchen K, Bjorksten B: Polyunsaturated n-3 fatty acids and the development of atopic disease. Lipids 2001;36:1033-1042.

2 Kompauer I, Demmelmair H, Koletzko B, Bolte G, Linseisen J, Heinrich J: Association of fatty acids in serum phospholipids with hay fever, specific and total immunoglobulin E. Br J Nutr 2005;93:529-535.

3 Trak-Fellermeier MA, Brasche S, Winkler G, Koletzko B, Heinrich J: Food and fatty acid intake and atopic disease in adults. Eur Respir J 2004;23:575-582.

4 Nakamura MT, Nara TY: Structure, function, and dietary regulation of delta6, delta5, and delta9 desaturases. Annu Rev Nutr 2004; 24:345-376.

5 Krauss-Etschmann S, Shadid R, Campoy C, Hoster E, Demmelmair H, Jimenez M, Gil A, Rivero M, Veszpremi B, Decsi T, Koletzko BV: Effects of fish-oil and folate supplementation of pregnant women on maternal and fetal plasma concentrations of docosahexaenoic acid and eicosapentaenoic acid: a European randomized multicenter trial. Am J Clin Nutr 2007;85:1392-1400.

6 Koletzko B, Demmelmair H, Schaeffer L, Illig T, Heinrich J: Genetically determined variation in polyunsaturated fatty acid metabolism may result in different dietary requirements. Nestle Nutr Workshop Ser Pediatr Program 2008;62:35-49.

7 Koletzko B, Larque E, Demmelmair H: Placental transfer of long-chain polyunsaturated fatty acids (LC-PUFA). J Perinat Med 2007;35(suppl 1):S5-S11.

8 Larque E, Demmelmair H, Klingler M, De Jonge S, Bondy B, Koletzko B: Expression pattern of fatty acid transport protein-1 (FATP-1), FATP-4 and heart-fatty acid binding protein (H-FABP) genes in human term placenta. Early Hum Dev 2006;82:697-701.

9 Koletzko B, Agostoni C, Carlson SE, Clandinin T, Hornstra G, Neuringer M, Uauy R, Yamashiro Y, Willatts P: Long chain polyunsaturated fatty acids (LC-PUFA) and perinatal development. Acta Paediatr 2001;90:460464.

10 Dunstan JA, Prescott SL: Does fish oil supplementation in pregnancy reduce the risk of allergic disease in infants? Curr Opin Allergy Clin Immunol 2005;5:215-221.

11 Field CJ, Thomson CA, Van Aerde JE, Parrott A, Euler A, Lien E, Clandinin MT: Lower proportion of CD45R0+ cells and deficient interleukin-10 production by formula-fed infants, compared with human-fed, is corrected with supplementation of longchain polyunsaturated fatty acids. J Pediatr Gastroenterol Nutr 2000;31:291-299.

12 Cho HP, Nakamura MT, Clarke SD: Cloning, expression, and nutritional regulation of the mammalian delta- 6 desaturase. J Biol Chem 1999;274:471-477.
13 Cho HP, Nakamura M, Clarke SD: Cloning, expression, and fatty acid regulation of the human delta-5 desaturase. J Biol Chem 1999; 274:37335-37339.

14 de Antueno RJ, Knickle LC, Smith H, Elliot ML, Allen SJ, Nwaka S, Winther MD: Activity of human delta 5 and delta 6 desaturases on multiple n-3 and n-6 polyunsaturated fatty acids. FEBS Lett 2001;509:77-80.

15 Voss A, Reinhart M, Sankarappa S, Sprecher $\mathrm{H}$ : The metabolism of 7,10,13,16,19-docosapentaenoic acid to 4,7,10,13,16,19-docosahexaenoic acid in rat liver is independent of a 4-desaturase. J Biol Chem 1991;266:1999520000.

16 Geiger M, Mohammed BS, Sankarappa S, Sprecher H: Studies to determine if rat liver contains chain-length-specific acyl-CoA 6 desaturases. Biochim Biophys Acta 1993; 1170:137-142.

17 D’andrea S, Guillou H, Jan S, Catheline D, Thibault JN, Bouriel M, Rioux V, Legrand P: The same rat delta6-desaturase not only acts on 18- but also on 24-carbon fatty acids in very-long-chain polyunsaturated fatty acid biosynthesis. Biochem J 2002;364:49-55.

18 Williard DE, Nwankwo JO, Kaduce TL, Harmon SD, Irons M, Moser HW, Raymond GV, Spector AA: Identification of a fatty acid delta6-desaturase deficiency in human skin fibroblasts. J Lipid Res 2001;42:501-508.

19 Marzo I, Alava MA, Pineiro A, Naval J: Biosynthesis of docosahexaenoic acid in human cells: evidence that two different delta 6-desaturase activities may exist. Biochim Biophys Acta 1996;1301:263-272.

20 Marzo I, Pineiro A, Naval J: Loss of delta6desaturase activity leads to impaired docosahexaenoic acid synthesis in Y-79 retinoblastoma cells. Prostaglandins Leukot Essent Fatty Acids 1998;59:293-297.

21 Marquardt A, Stohr H, White K, Weber BH: cDNA cloning, genomic structure, and chromosomal localization of three members of the human fatty acid desaturase family. Genomics 2000;66:175-183.

22 Park WJ, Kothapalli KS, Reardon HT, Kim LY, Brenna JT: Novel fatty acid desaturase 3 (FADS3) transcripts generated by alternative splicing. Gene 2009;446:28-34.

23 Guillou H, Rioux V, Catheline D, Thibault JN, Bouriel M, Jan S, D’andrea S, Legrand P: Conversion of hexadecanoic acid to hexadecenoic acid by rat Delta 6-desaturase. J Lipid Res 2003;44:450-454.

24 Rodriguez A, Sarda P, Nessmann C, Boulot P, Leger CL, Descomps B: Delta6- and delta5-desaturase activities in the human fetal liver: kinetic aspects. J Lipid Res 1998;39: 1825-1832.

25 Guillou H, D’andrea S, Rioux V, Jan S, Legrand $P$ : The surprising diversity of delta6desaturase substrates. Biochem Soc Trans 2004;32:86-87.
26 Park WJ, Kothapalli KS, Lawrence P, Tyburczy C, Brenna JT: An alternate pathway to long-chain polyunsaturates: the FADS2 gene product delta8-desaturates 20:2n-6 and 20:3n-3. J Lipid Res 2009;50:11951202.

27 Stoffel W, Holz B, Jenke B, Binczek E, Gunter RH, Kiss C, Karakesisoglou I, Thevis M, Weber AA, Arnhold S, Addicks K: Delta6desaturase (FADS2) deficiency unveils the role of omega3- and omega6-polyunsaturated fatty acids. EMBO J 2008;27:2281-2292.

28 Stroud CK, Nara TY, Roqueta-Rivera M, Radlowski EC, Lawrence P, Zhang Y, Cho BH, Segre M, Hess RA, Brenna JT, Haschek WM, Nakamura MT: Disruption of FADS2 gene in mice impairs male reproduction and causes dermal and intestinal ulceration. J Lipid Res 2009, E-pub ahead of print.

29 Schaeffer L, Gohlke H, Muller M, Heid IM, Palmer LJ, Kompauer I, Demmelmair H, Illig T, Koletzko B, Heinrich J: Common genetic variants of the FADS1 FADS2 gene cluster and their reconstructed haplotypes are associated with the fatty acid composition in phospholipids. Hum Mol Genet 2006; 15: 1745-1756

30 Malerba G, Schaeffer L, Xumerle L, Klopp N, Trabetti E, Biscuola M, Cavallari U, Galavotti R, Martinelli N, Guarini P, Girelli D, Olivieri O, Corrocher R, Heinrich J, Pignatti PF, Illig T: SNPs of the FADS gene cluster are associated with polyunsaturated fatty acids in a cohort of patients with cardiovascular disease. Lipids 2008;43:289-299.

31 Rzehak P, Heinrich J, Klopp N, Schaeffer L, Hoff S, Wolfram G, Illig T, Linseisen J: Evidence for an association between genetic variants of the fatty acid desaturase 1 fatty acid desaturase 2 (FADS1 FADS2) gene cluster and the fatty acid composition of erythrocyte membranes. Br J Nutr 2009;101:2026.

32 Xie L, Innis SM: Genetic variants of the FADS1 FADS2 gene cluster are associated with altered (n-6) and (n-3) essential fatty acids in plasma and erythrocyte phospholipids in women during pregnancy and in breast milk during lactation. J Nutr 2008;138:22222228.

33 Tanaka T, Shen J, Abecasis GR, Kisialiou A, Ordovas JM, Guralnik JM, Singleton A, Bandinelli S, Cherubini A, Arnett D, Tsai MY, Ferrucci L: Genome-wide association study of plasma polyunsaturated fatty acids in the InCHIANTI Study. PLoS Genet 2009;5: e1000338.

34 Hansen AE: Serum lipids in eczema and in other pathologic conditions. Am J Dis Child 1937; 53:933-946.

35 Manku MS, Horrobin DF, Morse NL, Wright S, Burton JL: Essential fatty acids in the plasma phospholipids of patients with atopic eczema. Br J Dermatol 1984;110:643-648. 
36 Strannegard IL, Svennerholm L, Strannegard O: Essential fatty acids in serum lecithin of children with atopic dermatitis and in umbilical cord serum of infants with high or low IgE levels. Int Arch Allergy Appl Immunol 1987;82:422-423.

37 Oliwiecki S, Burton JL, Elles K, Horrobin DF: Levels of essential and other fatty acids in plasma and red cell phospholipids from normal controls and patients with atopic eczema. Acta Derm Venereol 1991;71:224228

38 Griese M, Schur N, Laryea MD, Bremer HJ, Reinhardt D, Biggemann B: Fatty acid composition of phospholipids of plasma and of mononuclear blood cells in children with allergic asthma and the influence of glucocorticoids. Eur J Pediatr 1990;149:508-512.

39 Leichsenring M, Kochsiek U, Paul K: (n-6)fatty acids in plasma lipids of children with atopic bronchial asthma. Pediatr Allergy Immunol 1995;6:209-212.

40 Yu G, Bjorksten B: Polyunsaturated fatty acids in school children in relation to allergy and serum IgE levels. Pediatr Allergy Immunol 1998;9:133-138.

41 Rocklin RE, Thistle L, Gallant L, Manku MS, Horrobin D: Altered arachidonic acid content in polymorphonuclear and mononuclear cells from patients with allergic rhinitis and/or asthma. Lipids 1986;21:17-20.

42 Sakai K, Ueno K, Ogawa Y, Okuyama H: Fatty acid compositions of plasma lipids in young atopic patients. Chem Pharm Bull (Tokyo) 1986;34:2944-2949.

43 Lindskov R, Holmer G: Polyunsaturated fatty acids in plasma, red blood cells and mononuclear cell phospholipids of patients with atopic dermatitis. Allergy 1992;47:517-521.

44 Galli E, Picardo M, Chini L, Passi S, Moschese V, Terminali O, Paone F, Fraioli G, Rossi P: Analysis of polyunsaturated fatty acids in newborn sera: a screening tool for atopic disease? Br J Dermatol 1994;130:752756.

45 Yu G, Kjellman NI, Bjorksten B: Phospholipid fatty acids in cord blood: family history and development of allergy. Acta Paediatr 1996;85:679-683.

46 Beck M, Zelczak G, Lentze MJ: Abnormal fatty acid composition in umbilical cord blood of infants at high risk of atopic disease. Acta Paediatr 2000;89:279-284.

47 Duchen K, Casas R, Fageras-Bottcher M, Yu G, Bjorksten B: Human milk polyunsaturated long-chain fatty acids and secretory immunoglobulin A antibodies and early childhood allergy. Pediatr Allergy Immunol 2000; 11:29-39.

48 Yu G, Bjorksten B: Serum levels of phospholipid fatty acids in mothers and their babies in relation to allergic disease. Eur J Pediatr 1998;157:298-303.
49 Manku MS, Horrobin DF, Morse N, Kyte V, Jenkins K, Wright S, Burton JL: Reduced levels of prostaglandin precursors in the blood of atopic patients: defective delta-6-desaturase function as a biochemical basis for atopy. Prostaglandins Leukot Med 1982;9:615628.

50 Lans DM, Rocklin RE: Dysregulation of arachidonic acid release and metabolism by atopic mononuclear cells. Clin Exp Allergy 1989;19:37-44.

51 Needleman P, Turk J, Jakschik BA, Morrison AR, Lefkowith JB: Arachidonic acid metabolism. Annu Rev Biochem 1986;55:69-102.

52 Saito H, Ebisawa M, Tachimoto H, Shichijo M, Fukagawa K, Matsumoto K, Iikura $\mathrm{Y}$, Awaji T, Tsujimoto G, Yanagida M, Uzumaki H, Takahashi G, Tsuji K, Nakahata T: Selective growth of human mast cells induced by Steel factor, IL-6, and prostaglandin E2 from cord blood mononuclear cells. J Immunol 1996;157:343-350.

53 Roper RL, Brown DM, Phipps RP: Prostaglandin E2 promotes B lymphocyte Ig isotype switching to IgE. J Immunol 1995;154: 162-170.

54 Aloisi F, Penna G, Cerase J, Menendez IB, Adorini L: IL-12 production by central nervous system microglia is inhibited by astrocytes. J Immunol 1997;159:1604-1612.

55 Demeure CE, Yang LP, Desjardins C, Raynauld P, Delespesse G: Prostaglandin E2 primes naive $\mathrm{T}$ cells for the production of anti-inflammatory cytokines. Eur J Immunol 1997;27:3526-3531.

56 Dugas N, Dugas B, Kolb JP, Yamaoka K, Delfraiss JF, Damais C: Role of leukotriene B4 in the interleukin-4-induced human mononuclear phagocyte activation. Immunology 1996;88:384-388.

57 Khalfoun B, Thibault G, Lacord M, Gruel Y, Bardos P, Lebranchu Y: Docosahexaenoic and eicosapentaenoic acids inhibit human lymphoproliferative responses in vitro but not the expression of $T$ cell surface activation markers. Scand J Immunol 1996;43:248256.

58 Simopoulos AP: Omega-3 fatty acids in health and disease and in growth and development. Am J Clin Nutr 1991;54:438-463.

59 Stafford AN, Rider SH, Hopkin JM, Cookson WO, Monaco AP: A 2.8 Mb YAC contig in 11q12-q13 localizes candidate genes for atopy: Fc epsilon RI beta and CD20. Hum Mol Genet 1994;3:779-785.

60 Wheatley AP, Bolland DJ, Hewitt JE, Dewar JC, Hall IP: Identification of the autoantigen SART-1 as a candidate gene for the development of atopy. Hum Mol Genet 2002;11: 2143-2146.

61 Kramer MS: Does breast feeding help protect against atopic disease? Biology, methodology, and a golden jubilee of controversy. J Pediatr 1988;112:181-190.
62 Yu G, Duchen K, Bjorksten B: Fatty acid composition in colostrum and mature milk from non-atopic and atopic mothers during the first 6 months of lactation. Acta Paediatr 1998;87:729-736.

63 Thijs C, Houwelingen A, Poorterman I, Mordant A, van den BP: Essential fatty acids in breast milk of atopic mothers: comparison with non-atopic mothers, and effect of borage oil supplementation. Eur J Clin Nutr 2000;54:234-238.

64 Wright S, Bolton C: Breast milk fatty acids in mothers of children with atopic eczema. Br J Nutr 1989;62:693-697.

65 Businco L, Ioppi M, Morse NL, Nisini R, Wright S: Breast milk from mothers of children with newly developed atopic eczema has low levels of long chain polyunsaturated fatty acids. J Allergy Clin Immunol 1993;91: 1134-1139.

66 Luukkainen P, Salo MK, Nikkari T: Changes in the fatty acid composition of preterm and term human milk from 1 week to 6 months of lactation. J Pediatr Gastroenterol Nutr 1994;18:355-360

67 Biagi PL, Hrelia S, Celadon M, Turchetto E, Masi M, Ricci G, Specchia F, Cannella MV, Horrobin DF, Bordoni A: Erythrocyte membrane fatty acid composition in children with atopic dermatitis compared to agematched controls. Acta Paediatr 1993;82: 789-790.

68 Luukkainen P, Salo MK, Visakorpi JK, Raiha NC, Nikkari T: Impact of solid food on plasma arachidonic and docosahexaenoic acid status of term infants at 8 months of age. J Pediatr Gastroenterol Nutr 1996;23:229234

69 Ponder DL, Innis SM, Benson JD, Siegman IS: Docosahexaenoic acid status of term infants fed breast milk or infant formula containing soy oil or corn oil. Pediatr Res 1992; 32:683-688.

70 Akeson PM, Axelsson IE, Raiha NC: Plasma lipids and apolipoproteins in breastfed and formula-fed Swedish infants. Acta Paediatr 1999;88:1-6.

71 Fidler N, Sauerwald T, Pohl A, Demmelmair H, Koletzko B: Docosahexaenoic acid transfer into human milk after dietary supplementation: a randomized clinical trial. J Lipid Res 2000;41:1376-1383.

72 Marangoni F, Agostoni C, Lammardo AM, Bonvissuto M, Giovannini M, Galli C, Riva E: Polyunsaturated fatty acids in maternal plasma and in breast milk. Prostaglandins Leukot Essent Fatty Acids 2002;66:535-540.

73 Lattka E, Eggers S, Moeller G, Heim K, Weber M, Mehta D, Prokisch H, Illig T, Adamski J: A common FADS2 promoter polymorphism increases promoter activity and facilitates binding of transcription factor ELK1. J Lipid Res 2009, E-pub ahead of print. 